\title{
Isolamento e avaliação da atividade biológica dos alcalóides majoritários de Tabernaemontana angulata Mart. ex Müll. Arg., Apocynaceae
}

\author{
Camila M. de Assis, ${ }^{1}$ Paulo R. H. Moreno, ${ }^{2}$ Maria Claudia Marx Young, ${ }^{3}$ Ivan P. de Arruda \\ Campos, ${ }^{4}$ Ivana B. Suffredini ${ }^{*}, 1$
}

\author{
${ }^{1}$ Laboratório de Extração, Universidade Paulista, Av. Paulista, 900, $1^{\circ}$ andar, Bela Vista, 01310-100 \\ São Paulo-SP, Brasil \\ ${ }^{2}$ Instituto de Química, Universidade de São Paulo, Av. Lineu Prestes, 748, Bloco 11 superior, Butantã, 05513-970 \\ São Paulo-SP, Brasil \\ ${ }^{3}$ Instituto de Botânica, Secretaria do Meio Ambiente do Estado de São Paulo R. Miguel Stefano, 3687, 04301-902 \\ Água Funda, São Paulo-SP, Brasil \\ ${ }^{4}$ Programa de Pós-graduação em Engenharia de Produção, Instituto de Ciências Exatas e Tecnologia, \\ Universidade Paulista. R. Dr. Bacelar, 1212, Vila Clementino, 04026-002 São Paulo-SP, Brasil.
}

\begin{abstract}
RESUMO: A necessidade da introdução de novos agentes quimioterápicos é uma realidade no controle de doenças infecciosas. O Brasil é o país mais rico em biodiversidade, e o Laboratório de Extração da Universidade Paulista tem coletado plantas naAmazônia e MataAtlântica com a finalidade de identificar extratos vegetais antibacterianos e antitumorais. Estudos prévios demonstraram que a fração etanólica obtida do extrato bruto orgânico do caule de Tabernaemontana angulata Mart. ex Müll. Arg. apresentou atividade antimicrobiana significante contra Staphylococcus aureus ATCC6538, no ensaio de diluição em caldo. Verificou-se por cromatografia em camada delgada que os compostos majoritários presentes na fração ativa eram alcalóides. No presente trabalho, foi obtida a fração de alcalóides totais a partir do extrato bruto, da qual os compostos majoritários foram isolados por sucessivas cromatografias e, posteriormente, identificados por CG-EM e ${ }^{1} \mathrm{H}-$ RMN como os alcalóides indólicos coronaridina e voacangina. As frações obtidas do isolamento foram testadas no ensaio biológico, porém não demonstraram atividade antimicrobiana.
\end{abstract}

Unitermos: Tabernaemontana angulata, Apocynaceae, alcalóides, atividade antibacteriana, citotoxicidade.

\begin{abstract}
Isolation and evaluation of the biological activity related to the major alkaloids in Tabernaemontana angulata Mart. ex Müll. Arg., Apocynaceae." Introducing new chemotherapeutic agents is a great demand in the control of infectious diseases. Brazil is one of the richest countries in biodiversity and the Laboratório de Extração at UNIP has been collecting plants from the Amazon and Atlantic Rain Forests with the aim of screening for new antibacterial and antitumor plant extracts. Previous studies demonstrated that the ethanol fraction obtained from the crude extract of Tabernaemontana angulata stems showed an antibacterial activity against Staphylococcus aureus (ATCC 6538) in the microdilution broth assay. Two alkaloids were the major compounds in the active fraction, verified by thin layer chromatography analysis. In the present study, the total alkaloids were obtained from the crude extract and were fractionated by preparative thin layer chromatography for the isolation of the main components. The isolated compounds were identified by GC/MS and ${ }^{1} \mathrm{H}-\mathrm{NMR}$ as coronaridine and voacangine. The alkaloid fractions obtained from the isolation procedure were tested for antibacterial activity, but no activity was detected.
\end{abstract}

Keywords: Tabernaemontana angulata, Apocynaceae, alkaloids, antibacterial activity, cytotoxicity.

\section{INTRODUÇÃO}

As florestas tropicais possuem uma alta biodiversidade que, no Brasil, é estimada em $20 \%$ do total terrestre (Wilson \& Peter, 1988) e, na Amazônia, 17\% desse total (Brasil, 1998), proporcionando uma rica fonte de insumos a serem explorados (Milliken et al., 1992). Assim, a possibilidade de substâncias com potencial 
farmacológico serem descobertas no Brasil é muito grande (Suffredini \& Daly, 2001).

O Laboratório de Extração da UNIP mantém um programa de triagem de extratos vegetais de plantas da Amazônia e da Mata Atlântica a fim de selecionar os que apresentam atividade contra Staphylococcus aureus, Enterococus faecalis, Pseudomonas aeruginosa e Escherichia coli. Estudos prévios realizados com extratos de plantas da família das A pocynaceae, alguns apresentaram atividade contra as bactérias Gram positivas (Suffredini, 2000), dentre os quais o extrato bruto orgânico de caule de Tabernaemontana angulata Mart. ex Müll. Arg (Suffredini et al., 2002). Devido à atividade antibacteriana relevante observada para o material, decidiu-se isolar os componentes majoritários da amostra e testá-los no bioensaio e observar qual a variação de atividade antibacteriana encontrada para os compostos isolados. Ensaios prévios em cromatografia em camada delgada apontaram que os dois componentes majoritários eram alcalóides (Suffredini, 2000), além de que existe uma probabilidade de que alcalóides de Apocynaceae possam apresentar atividade antimicrobiana (Rojas Hernandez, 1979; van Beek et al., 1985, Munoz et al., 1994). Do extrato bruto seco (EB), foi obtida uma fração de alcalóides totais, denominada de AT, e desta, foram obtidas as frações denominadas 1, 2, 3, 4 e 5, e destas, subfrações, das quais os alcalóides foram isolados. Técnicas de espectroscopia em massas e ressonância magnética nuclear foram usadas para se identificar os compostos majoritários. O ensaio biológico usado para testar a atividade das amostras foi o método da diluição em caldo com a bactéria Staphylococcus aureus ATCC 6538 (Suffredini, 2000).

\section{MATERIAL E MÉTODOS}

\section{Procedimentos experimentais gerais}

\section{Ressonância magnética nuclear de hidrogênio-1}

Os espectros de $\mathrm{RMN}$ de ${ }^{1} \mathrm{H}$ foram obtidos de soluções a $0,01 \% \mathrm{v} / \mathrm{v}$ de substrato em $\mathrm{CDCl}_{3}$, contidas em tubos Wilmad 535-PP-7 de 5 mm de diâmetro externo, à temperatura ambiente $\left(c a .18{ }^{\circ} \mathrm{C}\right)$, utilizando-se o espectrômetro Varian UNITYINOVA $300\left({ }^{1} \mathrm{H}, 300 \mathrm{MHz}\right)$. Empregou-se, como referência, 0,003\% v/v de tetrametilsilano [TMS, $\delta\left({ }^{1} \mathrm{H}\right)=0$ ]. Parâmetros de aquisição: 3599 $\mathrm{Hz}$ de largura espectral; 4096 aquisições, contendo 29488 pontos de dados cada; $3 \mathrm{~s}$ de intervalo entre pulsos; 4.096 s de tempo de aquisição, resolução digital: $0,28 \mathrm{~Hz}$.

\section{Cromatografia a gás acoplada a espectrômetro de massas}

A análise dos extratos de alcalóides totais e dos produtos isolados foi realizada através de CG-EM. Para isso foi utilizado cromatógrafo a gás acoplado a espectrômetro de massas Agilent Series 6890, equipado com coluna HP-5 (30,0 m x 0,25 mm e filme de 0,25 $\mu \mathrm{m})$.

$\mathrm{O}$ gás de arraste utilizado foi Hélio, com fluxo contínuo de $1 \mathrm{~mL} / \mathrm{min}$; a energia de ionização empregada foi de $70 \mathrm{eV}$ e o volume de injeção de amostra, cuja concentração era de aproximadamente $0,1 \mathrm{mg} / \mathrm{mL}$, foi igual a 2,0 $\mu \mathrm{L}$. A temperatura do injetor era igual a 290 ${ }^{\circ} \mathrm{C}$. A temperatura inicial da coluna foi ajustada para 100 oC. Durante a análise, a temperatura inicial foi mantida por 1 min e, após foi aumentada com uma taxa de $10{ }^{\circ} \mathrm{C} /$ min até atingir a temperatura de $290{ }^{\circ} \mathrm{C}$ que foi mantida por $15 \mathrm{~min}$. Os espectros de massas assim obtidos foram comparados com o banco de espectros do próprio aparelho (Wiley 25) e também com dados de literatura (Gabetta \& Mustick, 1975).

\section{Reações de identificação dos grupos químicos}

Ensaios tradicionais para a identificação das principais classes químicas presentes no pó da planta foram realizados para flavonóides, taninos, antraquinonas, alcalóides, saponinas e glicosídeos cardioativos (Costa, 1994; Wagner \& Bladt, 1996).

\section{Material vegetal}

Caule de Tabernaemontana angulata Mart. ex Muell.Arg. foi coletado na região de Manaus situada às margens do rio Negro, latitude $3^{\circ} 2^{\prime} 52.7^{\prime}$, , longitude $60^{\circ}$ 18 '32.8", amostras foram depositadas no Herbário UNIP sob tombo 321 e número de coleta PSC 416, em 1997.

\section{Obtenção dos extratos}

\section{Extrato bruto}

Em função da necessidade de se isolar os compostos majoritários do caule de T. angulata, foi feita uma recoleta do material utilizando-se as informações obtidas anteriormente com GPS (global position system), a comparação de exsicatas e as anotações de campo registradas no banco de dados do Laboratório de Extração da UNIP. Do material recoletado, foram utilizados 761,10 $\mathrm{g}$ do caule previamente seco em estufa com circulação de ar a $40{ }^{\circ} \mathrm{C}$ e posteriormente moídos em moinho de martelo. O pó foi macerado em uma mistura de metanol e diclorometano $(1: 1 \mathrm{v} / \mathrm{v})$. Após 24 horas, o macerado foi drenado para um balão volumétrico, que foi então concentrado em um rota-evaporador. O procedimento foi repetido mais uma vez, e a maceração foi mantida por $72 \mathrm{~h}$. $\mathrm{O}$ macerado foi reunido ao anterior e o solvente eliminado à pressão reduzida e liofilizado. EB foi acondicionado em frasco âmbar para ser utilizado nos ensaios (Younes et al., 2000). 


\section{Isolamento dos alcalóides}

A fim de se otimizar a obtenção de alcalóides, optou-se por obter uma única fração de alcalóides totais. Para isso, a $30 \mathrm{~g}$ de EB, foram adicionados $300 \mathrm{~mL}$ de ácido clorídrico $1 \%$ e aquecidos em chapa por $10 \mathrm{~min}$. Após esfriar, a suspensão foi filtrada em papel de filtro. O filtrado foi alcalinizado com solução de amônia (10\%) até $\mathrm{pH} 10$, e extraído com clorofórmio até reação negativa com reagente de Dragendorff. As porções de clorofórmio obtidas foram reunidas, evaporadas obtendo-se 2,05 g de alcalóides totais (AT). Foi realizada a cromatografia em camada delgada preparativa (CCDP) para se isolar os dois componentes majoritários. Para isso, gel de sílica 60 $\mathrm{GF}_{254}$ (Merck) foi adicionada a suportes de vidro medindo 10x10 cm, com $0,800 \mathrm{~mm}$ de espessura. Utilizou-se fase móvel composta por metanol e clorofórmio (1:1) e, como reveladores, a luz UV $254 \mathrm{~nm}, 366 \mathrm{~nm}$ e o reagente de Dragendorff (Wagner \& Bladt, 1996). Para se fazer a análise das frações e subfrações obtidas, foram utilizadas fase móvel diclorometano e os mesmos reveladores acima mencionados. Ao final, foram obtidos os alcalóides coronaridina (1, 30,2 mg) e voacangina $(2,31,1 \mathrm{mg})$. As substâncias isoladas tiveram suas estruturas identificadas com base na comparação dos dados espectrais $\left({ }^{1} \mathrm{H}-\mathrm{RMN}\right.$ e $\mathrm{CG} / \mathrm{EM}$ ) com os dados da literatura.

\section{Coronaridina 1}

$\mathrm{R}_{\mathrm{f}} 0,74$ (DCM), ${ }^{1} \mathrm{H}-\mathrm{RMN}\left(\mathrm{CDCl}_{3}, 300 \mathrm{MHz}\right) \delta 7,81$ (sl, $1 \mathrm{H}, \mathrm{NH}), 7,46(d d, J$ 7,5 e 1,5 Hz, 1H), 7,23 (dd, J 7,5 e 1,5 $\mathrm{Hz}, 1 \mathrm{H}), 7,12(m, 2 \mathrm{H}), 3,75(s, 3 \mathrm{H}, \mathrm{COOMe}) ; 0,92(t, J 7,1$ $\mathrm{Hz}, 3 \mathrm{H}, \mathrm{Me})$; EM m/z $338\left(\mathrm{M}^{+}\right), 323\left(\mathrm{M}^{+}-\mathrm{Me}\right), 309\left(\mathrm{M}^{+}-\right.$ Et), $279\left(\mathrm{M}^{+}-\mathrm{CO}_{2} \mathrm{Me}\right), 253,214,148,136,130,122$.

\section{Voacangina 2}

$\mathrm{R}_{\mathrm{f}}$ 0,54 (DCM), ${ }^{1} \mathrm{H}-\mathrm{RMN}\left(\mathrm{CDCl}_{3}, 300 \mathrm{MHz}\right) \delta$ 7,72 $(\mathrm{sl}$, $1 \mathrm{H}, N H) 7,14(d, J 8,6 \mathrm{~Hz}, 1 \mathrm{H}) 6,92(\mathrm{~d}, \mathrm{~J} 2,5 \mathrm{~Hz}, 1 \mathrm{H}) 6,81$ $(d d, J 8,6$ e 2,5 Hz, 1H) 3,85 (s, 3H, OMe ) 3,71 (s, 3H, COOMe) 0,89 (t, J 7,0 Hz, 3H, Me). EM m/z $368\left(\mathrm{M}^{+}\right), 353$ $\left(\mathrm{M}^{+}-\mathrm{Me}\right), 339\left(\mathrm{M}^{+}-\mathrm{Et}\right), 309\left(\mathrm{M}^{+}-\mathrm{CO}_{2} \mathrm{Me}\right), 283,244,160$, $148,136,124,122$.

\section{Atividade antimicrobiana}

\section{Preparação e padronização das suspensões de microorganismo}

Staphylococcus aureus ATCC 6538 foi repicada em estrias na superfície do meio de cultura TSA em tubo inclinado, e foi incubada a $30-35^{\circ} \mathrm{C}$ por $24 \mathrm{~h}$. Os organismos viáveis foram recolhidos, em sua totalidade, em $9 \mathrm{~mL}$ de solução fisiológica estéril, e posteriormente contados, através da técnica de semeadura em profundidade. Para tanto, foi transferida uma gota da suspensão inicial para um tubo contendo $9 \mathrm{~mL}$ de solução fisiológica estéril. A partir desta nova suspensão, foram feitas diluições seriadas decimais, também em solução fisiológica estéril. Alíquotas de $1 \mathrm{~mL}$ das diluições $10^{-4}$ a $10^{-6}$ da suspensão de bactérias foram transferidas para placas de Petri, em duplicata, e homogeneizadas com cerca de $15 \mathrm{~mL}$ de meio de cultura TSB esterilizado. Seguindo-se o mesmo padrão de incubação descrito anteriormente, foi efetuada a contagem de unidades formadora de colônias (UFCs). A partir da suspensão original de cada microorganismo, cuja concentração passou a ser conhecida, foram efetuadas diluições em solução fisiológica estéril até obtenção de suspensão com concentração suficiente para obtenção de $1 \times 10^{2} \mathrm{UFC} / \mathrm{mL}$.

\section{Preparação das soluções de antibióticos}

Foi feita uma solução-mãe aquosa de gentamicina $10 \mathrm{mg} / \mathrm{mL}$. Desta solução, foram preparadas diluições de 40, 20 e $10 \mu \mathrm{g} / \mathrm{mL}$, empregando-se água destilada esterilizada, que representa uma concentração 20 vezes maior do que a testada nas microplacas. Para a obtenção da Concentração Inibitória Mínima (CIM) e da Concentração Bactericida Mínima (CBM) deste antibiótico, as concentrações finais usadas foram, portanto, de 2,0, 1,0 e 0,5 $\mu \mathrm{g} / \mathrm{mL}$.

\section{Preparação das soluções de $\mathrm{EB}, A T$ e subfrações derivadas de $A T$}

Concentrações de 25, 50, 60, 70, 80, 82, 84, $86,88,90,120$ e $200 \mathrm{mg} / \mathrm{mL}$ foram obtidas para EB, concentrações de 2,5, 5,0, 6,52, 10, 15 e $20 \mathrm{mg} / \mathrm{mL}$ foram obtidas para AT e concentrações de 2 e $4 \mathrm{mg} / \mathrm{mL}$ foram obtidas para as frações e subfrações para realizar os ensaios de determinação da CIM e da CBM de cada amostra.

\section{Determinação da atividade antimicrobiana e da concentração inibitória mínima e concentração bactericida mínima em microplacas de 96 poços}

Foram transferidos $190 \mu \mathrm{L}$ de suspensão bacteriana em meio TSB por poço da microplaca. As doses de antibiótico, extratos e frações foram distribuídas, em quadruplicata nos poços teste na quantidade de $10 \mu \mathrm{L}$ por poço, totalizando $200 \mu \mathrm{L}$ e perfazendo uma diluição de vinte vezes a concentração original. Poços foram usados como controle negativo de crescimento bacteriano (meio de cultura sem bactéria) e controle positivo de crescimento bacteriano (meio de cultura com bactéria). Após a inoculação, as microplacas foram mantidas em incubadora por $24 \mathrm{~h}$, a uma temperatura de $35^{\circ} \mathrm{C}$. Para a determinação da CIM e CBM, a mesma técnica foi utilizada, porém somente dois poços foram usados para cada concentração de amostra. Os resultados foram avaliados como $\mathrm{X}=$ botão, crescimento total de bactérias; $\mathrm{C}=$ crescimento parcial, com formação de turbidez expressiva; $++=$ crescimento parcial, sem formação de turbidez; +=crescimento parcial, com algumas colônias de bactérias visíveis e L=límpido, 
sem crescimento visual de colônias. Quando uma amostra é classificada com L no ensaio prévio, o meio na qual se encontra é submetido a uma subcultura em TSA e após $24 \mathrm{~h}$ de incubação a $35^{\circ} \mathrm{C}$, o crescimento bacteriano é reavaliado. Caso haja crescimento na subcultura a amostra é classificada como L+ e caso não haja crescimento em subcultura, a amostra é classificada como L-. Estes valores são usados para se determinar CIM e CBM. Em uma análise com concentrações sucessivas de uma mesma amostra, a menor concentração que resultou em L+ é tida como a concentração inibitória mínima e a menor concentração que apresentou L- é tida como a concentração bactericida mínima, para aquela condição experimental (Suffredini et al., 2004).

\section{Ensaio de citotoxicidade a células tumorais humanas}

O ensaio foi realizado segundo Monks et al. (1991) e está descrito a seguir. O conjunto de células a ser analisado é composto por tumores isolados de mama, próstata, pulmões, cólon, sistema nervoso central e sangue (células leucêmicas). As células são cultivadas em meio de cultura RPMI-1640 (Bio Whittaker) acrescido de 5\% de soro fetal bovino e $2 \mathrm{mM}$ de glutamina (ambos Bio Whittaker).

Semanalmente o meio de cultura celular é trocado e as células são transferidas para outro frasco, em menor quantidade de modo a permanecerem na fase log de crescimento. A quantidade de células é determinada, nessa fase, por contagem em hematocitômetro. A densidade celular necessária para cada célula deve ser vista na literatura especializada. As células são incubadas a 37 $\mathrm{oC}$, numa atmosfera com umidade relativa de $100 \%$ e $5 \%$ de $\mathrm{CO}_{2}$ por $24 \mathrm{~h}$ em frascos de crescimento apropriados e em microplacas de 96 poços, quando da realização dos experimentos. São feitos controles de crescimento e de inibição de crescimento utilizando-se agentes antitumorais conhecidos (doxorrubicina e 5-fluoruracila).

O extrato bruto orgânico seco obtido do caule de T. angulata foi diluído em DMSO 50\% a uma concentração inicial de $40 \mathrm{mg} / \mathrm{mL}$, para se obter uma diluição final, na placa, de 1: 400, portanto, realizou-se a determinação da porcentagem de crescimento causado pela dose única de $100 \mu \mathrm{g} / \mathrm{mL}$. A atividade dos extratos foi avaliada após $48 \mathrm{~h}$ da adição do extrato ao meio de cultura inoculado.

O resultado foi obtido através da leitura espectrofotométrica resultante da coloração obtida das células vivas cujas proteínas viáveis reagiram com a sulforrodamina B (SRB). A leitura foi feita em um leitor de microplacas espectrofotométrico em um comprimento de onda de $515 \mathrm{~nm}$. Obteve-se a densidade óptica dos poços correspondentes ao teste com os extratos, que foi comparada com a densidade óptica das células de controle de crescimento, sem tratamento. O cálculo utilizado para avaliação da inibição de crescimento $50 \%$ é [(T-T0) / $(\mathrm{C}-\mathrm{T} 0)]^{*} 100=\%$ crescimento.

\section{RESULTADOS E DISCUSSÃO}

Inicialmente, foi verificada, através de reações químicas com o material vegetal em pó, a presença de alcalóides e flavonóides no caule de T. angulata. $\mathrm{O}$ gênero Tabernaemontana é reconhecido pela produção de alcalóides indólicos (van Beek et al., 1984), que por hipótese, poderiam ser os responsáveis pela atividade antibacteriana anteriormente observada no extrato bruto (Tanaka et al., 2006). Desse modo, os alcalóides totais foram extraídos com o objetivo de se isolar os principais componentes dessa fração.

Os compostos majoritários presentes nos alcalóides totais foram isolados por sucessivas etapas de cromatografia em camada preparativa sendo os compostos isolados analisados por CG-EM e ${ }^{1} \mathrm{H}-\mathrm{RMN}$ e os dados espectrais foram comparados com dados da literatura (Perera et al., 1983) indicando que os mesmos tratavamse da voacangina 1 e da coronaridina 2. Estes alcalóides são comumente encontrados em espécies do gênero Tabernaemontana com ocorrência no Brasil, tais como T. fuchsiaefolia, T. divaricata, T. catharinensis e T. laeta (Andrade et a., 2005; Zocoler et al., 2005; Pereira et al., 2004; Medeiros et al., 2001)

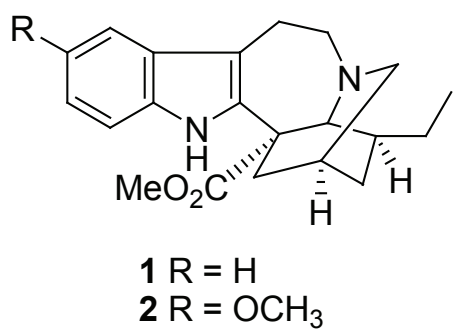

No ensaio para atividade antibacteriana o extrato bruto apresentou uma CIM de $4,0 \mathrm{mg} / \mathrm{mL}$ e CBM de $8,0 \mathrm{mg} / \mathrm{mL}$ (Tabela 1 ), já os alcalóides totais bem como todas as frações obtidas da separação cromatográfica dos mesmos não apresentaram atividade.

Acoronaridina foi o composto majoritário da fração de alcalóides totais obtida de EB. A atividade antibacteriana observada possivelmente não está relacionada à presença deste composto uma vez as frações onde este composto estava presente não foram ativas. Este alcalóide possui diversas atividades biológicas comprovadas, tais como anticolinesterásica (Andrade et al., 2005), hipotensora (Perera et al., 1985), contraceptiva (Farnsworth et al., 1975), citotóxica (Kam et al., 2004), contra câncer de ovário (Prakash Chaturvedula et al., 2003), leishmanicida (Delorenzi et al., 2002), antiinflamatória (Henriques et al., 1996), analgésica e hipotérmica (Okuyama et al., 1992), porém não se encontram relatos referentes à atividade antibacteriana para coronaridina. Por outro lado, o segundo composto majoritário, a voacangina, demonstrou atividade frente a diferentes espécies de Mycobacterium (Rastogi

\begin{tabular}{r|r}
\hline Rev. Bras. Farmacogn. & 629 \\
Braz. J. Pharmacogn. & 629 \\
19(2B): Abr./Jun. 2009 &
\end{tabular}


et al., 1998). Como, além de alcalóides, foi verificada a presença de flavonóides no extrato bruto, pode-se levantar a hipótese de que a atividade biológica observada poderia estar relacionada a esta classe, comum em espécies de Apocynaceae (Schroder et al., 2004, Chattopadhyay et al., 2006).

Adicionalmente, o extrato bruto foi testado em seis células tumorais humanas para avaliação do grau de citotoxicidade. Como mostrado na Tabela 2, não houve inibição de crescimento acentuada em nenhuma das células tumorais testadas, portanto, o extrato do caule de T. angulata não apresenta atividade citotóxica, embora haja relatos na literatura referentes à atividade citotóxica de coronaridina (Kam et al., 2004; Prakash Chaturvedula, 2003).

Tabela 1. Resultados referentes aos ensaios antibacterianos realizados com o extrato bruto (EB) e frações (AT, 4D e 5E), obtidas a partir do caule de T. angulata.

\begin{tabular}{lcc}
\hline & CIM $(\mathrm{mg} / \mathrm{mL})$ & CBM $(\mathrm{mg} / \mathrm{mL})$ \\
\hline EB & 4,0 & 8,0 \\
AT & - & - \\
4D (voacangina) & - & - \\
5 E (coronaridina) & - & - \\
Eritromicina & 0,1 & 0,1 \\
Gentamicina & 0,1 & 0,1 \\
Tetraciclina & 0,1 & 0,1 \\
\hline- atividade antibacteriana & não & representativa nas doses \\
analisadas. & &
\end{tabular}

Tabela 2. Resultados obtidos da análise citotóxica do extrato bruto EB obtido do caule de Tabernaemontana angulata contra células tumorais humanas de mama (MCF-7), próstata (PC-3), pulmão (NCI-H460), cólon (KM-12), sistema nervoso central (SF-268) e células leucêmicas (RPMI-8226).

\begin{tabular}{lc}
\hline \multicolumn{2}{c}{$\%$ crescimento* $^{*}$} \\
\hline Células testadas & EB \\
MCF-7 & 102,11 \\
PC-3 & 90,66 \\
NCI-H460 & 73,36 \\
KM-12 & 105,44 \\
SF-268 & 79,56 \\
RPMI-8226 & 107,10 \\
\hline
\end{tabular}

* Os resultados expressam a porcentagem de crescimento frente a controles de crescimento sem tratamento.

\section{REFERÊNCIAS}

Andrade MT, Lima JA, Pinto AC, Rezende CM, Carvalho MP, Epifanio RA 2005. Indole alkaloids from Tabernaemontana australis (Muell. Arg) Miers that inhibit acetylcholinesterase enzyme. Bioorg Med Chem 13: 4092-4095.

Brasil 1998. Ministério do Meio Ambiente, dos Recursos Hídri- cos e da Amazonia Legal. Primeiro relatório nacional para a convenção sobre diversidade biológica. Brasília: Ministério do Meio Ambiente, 283 p.

Chattopadhyay D, Arunachalam G, Mandal AB, Bhattacharya SK 2006. Dose-dependent therapeutic antiinfectives from ethnomedicines of bay islands. Chemotherapy 52 : 151-157.

Costa AF 1994. Farmacognosia. Lisboa: Fundação Calouste Gulbenkian.

Delorenzi JC, Freire De Lima L, Gattass CR, De Andrade Costa D, Kuehne ME, Saraiva EM 2002. In vitro activities of iboga alkaloid congeners coronaridine and 18-methoxycoronaridine against Leishmania amazonensis. Antimicrob Agents Chemother 46: 2111-2115.

Farnsworth NR, Bingel AS, Cordell GA, Crane FA, Fong HH 1975. Potential value of plants as sources of new antifertility agents. J Pharm Sci 64: 535-598.

Gabetta B, Mustick G 1975. Spectral data of indole alkaloids; Milão: Inverni Della Beffa.

Henriques AT, Melo AA, Moreno PRH, Ene LL, Henriques JA, Schapoval EE 1996. Ervatamia coronaria: Chemical constituents and some pharmacological activities. $J$ Ethnopharmacol 50: 19-25.

Kam TS, Sim KM, Pang HS, Koyano T, Hayashi M, Komiyama K 2004. Cytotoxic effects and reversal of multidrug resistance by ibogan and related indole alkaloids. Bioorg Med Chem Lett 14: 4487-4489.

Medeiros WLB, Vieira IJC, Mathias L, Braz R, Schripsema J 2001. A new natural quaternary indole alkaloid isolated from Tabernaemontana laeta Mart. (Apocynaceae). $J$ Braz Chem Soc 12: 368-372.

Milliken W, Miller RP, Pollard SR, Wandelli EV 1992. Ethnobotany of the Waimiri Atroari indians of Brazil. Kent: Royal Botanical Gardens.

Monks A, Scudiero D, Skehan P, Shoemaker R, Paull K, Vistica D, Hose C, Langley J, Cronise P, Vaigro-Wolff A, GrayGoodrich M, Campbell H, Mayo J, Boyd M 1991. J Natl Cancer Inst 83:757-766.

Munoz V, Moretti C, Sauvain M, Caron C, Porzel A, Massiot G, Richard B, Le Men-Olivier L 1994. Isolation of bis-indole alkaloids with antileishmanial and antibacterial activities from Peschiera van heurkii (syn. Tabernaemontana van heurkii). Planta Med 60: 455-459.

Okuyama E, Gao LH, Yamazaki M 1992. Analgesic components from Bornean medicinal plants, Tabernaemontana pauciflora Blume and Tabernaemontana pandacaqui Poir. Chem Pharm Bull 40: 2075-2079.

Prakash Chaturvedula VS, Sprague S, Schilling JK, Kingston DG 2003. New cytotoxic indole alkaloids from Tabernaemontana calcarea from the Madagascar rainforest. J Nat Prod 66: 528-531.

Perera P, Sandberg F, Van Beek TA, Verpoorte R 1983. Tertiary indole alkaloids of Tabernaemontana dichotoma seeds. Planta Med 49: 28-31.

Perera P, Kanjanapothy D, Sandberg F, Verpoorte R 1985. Muscle relaxant activity and hypotensive activity of some Taber- 
naemontana alkaloids. J Ethnopharmacol 13: 165-173.

Pereira CG, Marques MOM, Barreto AS, Siani AC, Fernandes EC, Meireles MAA 2004. Extraction of indole alkaloids from Tabernaemontana catharinensis using supercritical $\mathrm{CO} 2$ plus ethanol: an evaluation of the process variables and the raw material origin. J Supercrit Fluids 30: 5161.

Rastogi N, Abaul J, Goh KS, Devallois A, Philogeéne E, Bourgeois P 1998. Antimycobacterial activity of chemically defined natural substances from the Caribbean flora in Guadeloupe. FEMS Immunol Med Mic 20: 267-273.

Rojas-Hernandez NM 1979. Evaluation of antimicrobial activity of indol alkaloids. Rev Cubana Med Trop 31: 199-204.

Schroder G, Wehinger E, Lukacin R, Wellmann F, Seefelder W, Schwab W, Schroder J 2004. Flavonoid methylation: a novel 4'-O-methyltransferase from Catharanthus roseus, and evidence that partially methylated flavanones are substrates of four different flavonoid dioxygenases. Phytochemistry 65: 1085-94.

Suffredini IB 2000. Avaliação citotóxica, antiviral e antimicrobiana de Apocynaceae amazônicas. Tese de Doutorado, Faculdade de Ciências Farmacêuticas, Universidade de São Paulo.

Suffredini IB, Bacchi EM, Sakuda TMK, Ohara MT, Younes RN, Varella AD 2002. Antibacterial activity of Apocynaceae extracts and MIC of Tabernaemontana angulata stem organic extract. Rev Bras Cienc Farm 38: 89-94.

Suffredini IB, Daly D 2001. O Rio Negro como cenário na busca de novos medicamentos In: Oliveira, A.A.; Daly, D.C. Florestas do Rio Negro. São Paulo: Companhia das Letras.

Suffredini IB, Sader HS, Gonçalves AG, Reis AO, Gales AC, Varella AD, Younes RN 2004. Screening of antibacterial active extracts obtained from plants native to Brazilian Amazon rain forest and Atlantic forest. Braz J Med Biol Res 37: 379-384.

Tanaka JC Silva CC, Oliveira AJ Nakamura CV, Dias Filho BP 2006. Antibacterial activity of indole alkaloids from $\mathrm{As}$ pidosperma ramiflorum. Braz J Med Biol Res 39: $387-$ 391.

Van Beek TA, Verpoorte R, Svendsen AB, Foklens R 1985. Antimicrobially active alkaloids from Tabernaemontana chippii. J Nat Prod 48: 400-23.

Van Beek TA, Van Deelder AM, Verpoorte R, Svendsen A 1984. Antimicrobial, antiamoebic and antiviral screening of some Tabernaemontana species. Planta Med 50: 180185.

Wagner H, Bladt S 1996. Plant drug analysis. Berlin: Springer Verlag.

Wilson EO, Peter FM 1988. Biodiversity. Washington: National Academic Press.

Younes RN, Varella AD Suffredini IB 2000. Extração e rastreamento de novas drogas em plantas brasileiras. Acta Oncol Bras 20: 15-19.

Zocoler MA, De Oliveira AJB, Sarragiotto MH, Grzesiuk VL, Vidotti GJ 2005. Qualitative determination of indole a kaloids of Tabernaemontana fuchsiaefolia (Apocynaceae). J Braz Chem Soc 16: 1372-1377. 